\title{
INFLUENCE OF SOCIODEMOGRAPHIC FACTORS ON HELICOBACTER PYLORI PREVALENCE VARIABILITY AMONG SCHOOLCHILDREN IN LEIPZIG, GERMANY. A LONG-TERM FOLLOW-UP STUDY
}

\author{
Sophie Bauer ${ }^{1}$, Peter Krumbiegel2 ${ }^{2}$ Matthias Richter², Thomas Richter ${ }^{3}$, Stefan Röder², Ulrike Rolle-Kampczyk², \\ Olf Herbarth ${ }^{1}$ \\ ${ }^{1}$ Institute of Environmental Medicine and Hygiene, Faculty of Medicine, University of Leipzig, Leipzig, Germany \\ ${ }^{2}$ Department of Human Exposure Research and Epidemiology, (UFZ) Leipzig-Halle, Leipzig, Germany \\ 3Municipal Children's Hospital "St. Georg", Leipzig, Germany
}

\section{SUMMARY}

Background: Until the beginning of this decade the assumption was that the Helicobacter pylori prevalence increases with the age of the population under consideration. More and more epidemiological studies have been suggestive of constancy in Helicobacter pylori prevalence, but to date there has been no long-term follow-up study in a large group of children confirming this hypothesis.

Methods: Following up our study of H. pylori among school starters and 2nd graders in 1998 and 2000, we conducted a third phase of this study in 2006 using the $\left[{ }^{13} \mathrm{C}\right]-$ Urea Breath Test and a detailed parent-completed epidemiological questionnaire to evaluate the development of prevalence among the overall population of 8th graders in the city of Leipzig $(n=1,905)$, and especially of the subgroup of participants who took part in all three study phases $(n=751)$.

Results: The overall $H$. pylori prevalence was $6.5 \%$ and had not significantly changed since 1998 and 2000 ( $6.1 \%, 5.7 \%$ respectively). However, we noticed a significant lower prevalence in the subgroup that participated in all study phases $(2.7 \%)$. Moreover, we observed a dependence of prevalence on distribution of sociodemographic risk factors such as foreign nationality of at least one parent, birth outside of Germany, low parental education and unemployment, and $\geq 2$ older siblings.

Conclusion: The variability in prevalence is most likely a result of unequal sociodemographic family backgrounds.

Key words: helicobacter pylori, bacterial disease, child health, childhood infections, environmental health, social factors

Address for correspondence: $\mathrm{O}$. Herbarth, Institute of Environmental Medicine and Hygiene, Faculty of Medicine, University Leipzig, Liebigstraße 27, 04103 Leipzig, Germany. E-mail: olf.herbarth@medizin.uni-leipzig.de

\section{INTRODUCTION}

It is well known that Helicobacter plyori infection is the main risk factor for upper gastrointestinal tract disorders leading to gastric malignancies in adulthood (1). The impact of sociodemographic factors on infection status has been indicated in numerous studies (2-4). In the developing world the prevalence is significantly higher when compared to developed countries (5). Overall, approximately half of the world's population is estimated to be colonized with $H$. pylori, which has a major impact on public health. Infection is mainly acquired in early childhood (6-8). In developed countries for the first time it could be shown in a study with more than 2000 study participants, that the prevalence between 6 and 9 years is largely unchanged (9). Other studies have also been suggestive of constancy in prevalence after the age of 4 years, but to date there has been no long-term follow-up study in large groups of children to confirm these findings (10-12). Cross-sectional follow-up studies have been conducted and have shown a declining prevalence in younger birth cohorts due to improving living conditions and widespread use of antibiotic substances $(13,14)$.
The first cross-sectional H. pylori study in Leipzig was conducted in 1998 in school starters aged 5-7 to determine the H. pylori infection status of an almost complete birth cohort. Overall prevalence was $6.2 \%$ (15). A follow-up study 2 years later (study phase 2) did not reveal any significant change in prevalence $(5.7 \%)$.

In 2006 we conducted the third and final phase of the study to determine the development of prevalence over time in German school children. To our knowledge, this is the first populationbased long-term follow-up study in a large group of asymptomatic schoolchildren in a developed country.

\section{MATERIAL AND METHODS}

The third phase of the Leipzig Helicobacter pylori study was designed as a repeated population-based cross-sectional study, which was conducted between February and June 2006 as a joint project of the Department of Human Exposure Research and Epidemiology, Centre for Environmental Research Leipzig-Halle 
(UFZ); the Institute of Environmental Medicine and Hygiene, Faculty of Medicine, University of Leipzig; and the St. Georg Municipal Children's Hospital. In 2006 the non-invasive UBT $\left(\left[{ }^{13} \mathrm{C}\right]\right.$-Urea Breath Test) was offered to all 2,994 schoolchildren attending 8th grade in the city of Leipzig (average age 14.6 years \pm 0.7 years, range 13.1-18.6). Our Helicobacter pylori Study group collected data from 1,905 children who presented written parental informed consent. During the first lesson at school $H$. pylori infection status was assessed using the UBT. The study protocol as well as the study population of the first two study phases have been described elsewhere in detail $(15,16)$. Of note, the nonsignificant difference between $6.1 \%$ and $6.2 \%$ is a result of the varying number of complete data sets for the variables included in the different study phases. To summarize, the test consisted of two breath samples, one taken before and another 30 minutes after ingestion of $\left[{ }^{13} \mathrm{C}\right]$-urea. For analysis non-dispersive infrared spectroscopy was used. In total $1,905(63.3 \%)$ children handed in a detailed parent-completed questionnaire on sociodemographic factors and were thus included into our study.

Complete data sets consisting of $H$. pylori infection status as well as the epidemiologic questionnaire of each study phase were available for 751 children, which allowed the exact analysis of prevalence development in this subgroup (from now on called 'Group A'). Furthermore, a comparison with the other part of the overall population (from now on 'Group B') could be drawn to see whether Group A represents the overall population.

Given the fact that sociodemographic factors have a major impact on H. plylori infection status, we decided to identify risk factors for the overall study population and compare their distribution among the two subgroups. The sociodemographic factors included in our analysis were foreign nationality of at least one parent, birth outside of Germany, crowding index $<25 \mathrm{~m}^{2}$ (defined as number of persons per household divided by living space), low parental education (defined as graduation from an intermediate secondary school or lower), unemployment of parents (defined as unemployment of both parents or of a single mother/single father), $\geq 2$ older siblings, and roomsharing with siblings.

Statistical analysis (prevalence, adjusted OR, logistic regression models) was performed using STATISTICA for Windows Version 7.1. (StatSoft, Inc. 2005), level of significance $\mathrm{p}=0.05$.

The study was approved by the ethics committee of the University of Leipzig. City of Leipzig authorities gave permission for the participation of schoolchildren in the study.

\section{RESULTS}

Among the 1,905 8th graders in 2006 the overall prevalence of $H$. pylori was $6.5 \%(\mathrm{n}=123)$. Compared to the previous two study phases in 1998 and 2000, no significant change in infection rate could be appreciated (6.1\%, 5.7\% respectively). Dividing the overall study population into those who participated in all three study parts (Group A) and those who did not (Group B), a significant lower prevalence for Group A was noticed (see Fig. 1). Consequently, Group A does not adequately represent the overall population. To determine the cause of the difference in prevalence, we developed the hypothesis that sociodemographic factors impacted on our study population and that Group A and Group B differ in distribution of the risk factors.

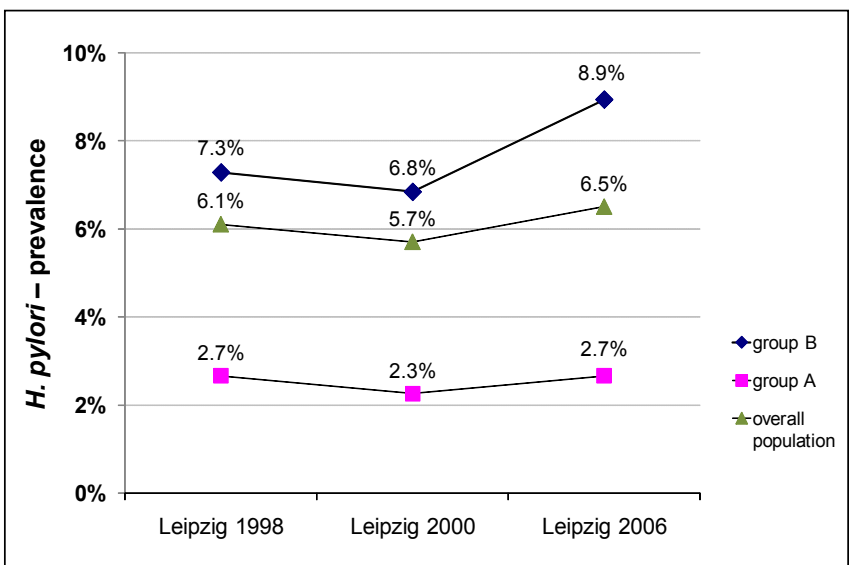

Fig. 1. H. pylori prevalence-follow-up study. Group $A$ : $N=751$; Group B (1998): N=2,088; Group $B$ (2000): $N=2,253$; Group $B$ (2006): $N=1,154$. In all three study phases the $H$. pylori prevalence of Group $A$ is significantly below the infection rate of Group $B(p<0.001)$.

Including the above-mentioned variables in the logistic regression models, we identified birth outside of Germany ( $O R=10.3$; 95\% CI: $6.0-17.7 ; \mathrm{p}<0.001)$, foreign nationality of at least one parent $(\mathrm{OR}=4.4 ; 95 \% \mathrm{CI}: 2.7-7.2 ; \mathrm{p}<0.001)$, low parental education $(\mathrm{OR}=2.8 ; 95 \% \mathrm{CI}: 1.8-4.5 ; \mathrm{p}<0.001), \geq 2$ older siblings $(\mathrm{OR}=2.3 ; 95 \% \mathrm{CI}: 1.4-2.9 ; \mathrm{p}=0.002)$ and unemployment of parents $(\mathrm{OR}=1.7 ; 95 \% \mathrm{CI}: 1.1-2.8 ; \mathrm{p}=0.039)$ to be significantly associated with $H$. pylori colonization.

Table 1 summarizes the comparison of the two subgroups and clearly shows the significant difference in distribution of the sociodemographic risk factors. Children belonging to Group B have a more sociodemographic-disadvantaged family background compared to Group A.

\section{DISCUSSION}

The results of our third study phase confirm the findings of Granquist and Granström by showing no significant change in $H$. pylori prevalence in our asymptomatic population of schoolchildren over an 8-year period $(10,12)$. Both the overall prevalence and the prevalence in each subgroup remained constant. Surprisingly, a significant difference in prevalence was revealed when the two subgroups were compared. Consequently the children who participated in all three study phases (Group A) do not adequately represent the overall study population of 2006. A model of explanation may be developed by looking at the distribution of sociodemographic risk factors among the two subgroups. The association between $H$. pylori infection and birth outside of Germany, foreign nationality of parents, low parental education and high number of older siblings has been described in previous studies (2, 3, 17-19). Additionally, we identified parental unemployment as a significant risk factor, which indirectly reflects low family income (2). The variability in prevalence between Group A and Group B can be explained by taking the sociodemographic risk factors into account and considering their significant difference in distribution.

Other risk factors which influence the prevalence have been described in Herbarth et al. (15). A further avenue for research 
Table 1. Distribution of sociodemographic risk factors. Comparison of Group A and B

\begin{tabular}{|l|c|c|c|c|}
\hline Risk factor & Group A & Group B & p-value* & Total \\
\hline Parental nationality & & & $<0.001$ & $\mathrm{~N}=1,831$ \\
\hline German & $703(96.2 \%)$ & $958(87.1 \%)$ & & $1,661(90.7 \%)$ \\
\hline Other & $28(3.8 \%)$ & $142(12.9 \%)$ & & $170(9.3 \%)$ \\
\hline Country of birth & & & $<.001$ & $\mathrm{~N}=1,904$ \\
\hline Germany & $741(98.7 \%)$ & $1050(91.1 \%)$ & & $1,791(94.1 \%)$ \\
\hline Other & $10(1.3 \%)$ & $103(8.9 \%)$ & & $113(5.9 \%)$ \\
\hline Parental education & & & $<0.001$ & $\mathrm{~N}=1,861$ \\
\hline Low & $121(16.2 \%)$ & $284(25.4 \%)$ & $<0.001$ & $405(21.8 \%)$ \\
\hline Middle & $262(35.2 \%)$ & $390(35 \%)$ & 0.922 & $652(35 \%)$ \\
\hline High & $362(48.6 \%)$ & $442(39.6 \%)$ & $<0.001$ & $804(43.2 \%)$ \\
\hline Parental unemployment & & & $<0.001$ & $\mathrm{~N}=1,905$ \\
\hline No & $685(91.2 \%)$ & $925(80.2 \%)$ & & $1,610(84.5 \%)$ \\
\hline Yes & $66(8.8 \%)$ & $229(19.8 \%)$ & & $295(15.5 \%)$ \\
\hline No. of older siblings & & & & $\mathrm{N}=1,888$ \\
\hline 0 & $461(61.9 \%)$ & $629(55.0 \%)$ & $<0.001$ & $1,090(57.7 \%)$ \\
\hline 1 & $234(31.4 \%)$ & $370(32.4 \%)$ & 0.003 & $604(32.0 \%)$ \\
\hline$\geq 2$ & $50(6.7 \%)$ & $144(12.6 \%)$ & 0.66 & $194(10.3 \%)$ \\
\hline
\end{tabular}

*Pearson's $\mathrm{X}^{2}$ Test $\mathrm{p}<0.05$

would be to investigate whether these previously identified risk factors are associated with the sociodemographic ones. It should be mentioned that patients with positive test results received a notification and were offered a one-on-one consultation which included a discussion about potential risk factors and preventative measures.

In summary, this investigation showed a variability of prevalence in a large number of schoolchildren from the same city, which seems to have resulted from different sociodemographic family backgrounds. The unchanged overall and subgroup prevalences corroborate the cohort phenomenon hypothesis (20). It appears likely that infection occurs between birth and preschool age and persists over life time if untreated. All sociodemographic risk factors trace back to poor hygiene practice during early childhood. This study has clearly shown the need for educational initiatives to promote good household hygiene and reduce the infection rate for this potentially preventable disease.

\section{ACKNOWLEDGEMENTS}

We thank University Children's Hospital, Public Health Department, Leipzig (first phase of the study), Public Health Services, City and County of Leipzig. We are grateful to all of the participating doctors and technical staff of the Public Health Services, Division of Children and Adolescents, City and County of Leipzig, for incorporating our study into their work schedule and the medical students for carrying out the tests. We especially thank all of the children and their parents for their interest and participation in the study.

\section{FUNDING}

Parts of the study were supported by the BMBF Federal Ministry of Education and Research (Germany), the UFZ (Grant No. UFZ-20/97), and State Ministry of Family and Health Saxony (Grant No. WVSMS/2001).

\section{REFERENCES}

1. Kandulski A, Selgrad M, Malfertheiner P. Helicobacter pylori infection: a clinical overview. Dig Liver Dis. 2008 Aug;40(8):619-26.

2. Cheng H, Hu F, Zhang L, Yang G, Ma J, Hu J, et al. Prevalence of Helicobacter pylori infection and identification of risk factors in rural and urban Beijing, China. Helicobacter. 2009 Apr;14(2):128-33.

3. Nouraie M, Latifi-Navid S, Rezvan H, Radmard AR, Maghsudlu M, Zaer-Rezaii $\mathrm{H}$, et al. Childhood hygienic practice and family education status determine the prevalence of Helicobacter pylori infection in Iran. Helicobacter. 2009 Feb;14(1):40-6.

4. Sýkora J, Fiala K, Varvarovská J, Pazdiora P, Pomahačová R, Huml M. Epidemiology of Helicobacter pylori infection in asymptomatic children: a prospective population-based study from the Czech Republic. Application of a monoclonal-based antigen-in-stool enzyme immunoassay. Helicobacter. 2009 Aug;14(4):286-97.

5. Bruce MG, Maaroos HI. Epidemiology of Helicobacter pylori infection. Helicobacter. 2008 Oct;13 Suppl 1:1-6.

6. Goodman KJ, Correa P. Transmission of Helicobacter pylori among siblings. Lancet. 2000 Jan 29;355(9201):358-62.

7. Rowland M, Daly L, Vaughan M, Higgins A, Bourke B, Drumm B. Age-specific incidence of Helicobacter pylori. Gastroenterology. 2006 Jan;130(1):65-72; quiz 211.

8. Muhsen K, Athamna A, Bialik A, Alpert G, Cohen D. Presence of Helicobacter pylori in a sibling is associated with a long-term increased risk of H. pylori infection in Israeli Arab children. Helicobacter. 2010 Apr;15(2):108-13.

9. Krumbiegel P, Nicklisch C, Herbarth O, et al. $13 \mathrm{C}$ Helicobacter pylori test with Leipzig's birth cohort 1991/1992: prevalence, incidences and their local distribution [abstract]. Isotopes Environ Health Stud. 2000;36:337.

10. Granquist A, Bredberg A, Sveger T, Axelsson I. A longitudinal cohort study on the prevalence of Helicobacter pylori antibodies in Swedish children and adolescents. Acta Paediatr. 2002;91(6):636-40.

11. Ashorn M, Mäki M, Hällström M, Uhari M, Akerblom HK, Viikari J, et al. Helicobacter pylori infection in Finnish children and adolescents. A serologic cross-sectional and follow-up study. Scand J Gastroenterol. 1995 Sep;30(9):876-9.

12. Granström M, Tindberg Y, Blennow M. Seroepidemiology of Helicobacter pylori infection in a cohort of children monitored from 6 months to 11 years of age. J Clin Microbiol. 1997 Feb;35(2):468-70. 
13. Tkachenko MA, Zhannat NZ, Erman LV, Blashenkova EL, Isachenko SV, Isachenko OB, et al. Dramatic changes in the prevalence of Helicobacter pylori infection during childhood: a 10-year follow-up study in Russia. J Pediatr Gastroenterol Nutr. 2007 Oct;45(4):428-32.

14. Rothenbacher D, Schultze V, Jähnig P, Scharschmidt B, Brenner H. Evidence of a rapid decrease in prevalence of Helicobacter pylori infection in children of a high risk group living in Germany. Eur J Pediatr. 2004 Jun;163(6):339-40.

15. Herbarth O, Krumbiegel P, Fritz GJ, Richter M, Schlink U, Müller DM, et al. Helicobacter pylori prevalences and risk factors among schoo beginners in a German urban center and its rural county. Environ Health Perspect. 2001 Jun;109(6):573-7.

16. Strebel K, Rolle-Kampczyk U, Richter M, Kindler A, Richter T, Schlink U. A rigorous small area modelling-study for the Helicobacter pylori epidemiology. Sci Total Environ. 2010 Aug 15;408(18):393142 .
17. Rothenbacher D, Bode G, Berg G, Gommel R, Gonser T, Adler G, et al. Prevalence and determinants of Helicobacter pylori infection in preschool children: a population-based study from Germany. Int J Epidemiol. 1998 Feb;27(1):135-41.

18. Tam YH, Yeung CK, Lee KH, Sihoe JD, Chan KW, Cheung ST, et al. A population-based study of Helicobacter pylori infection in Chinese children resident in Hong Kong: prevalence and potential risk factors. Helicobacter. 2008 Jun;13(3):219-24.

19. Koch A, Krause TG, Krogfelt K, Olsen OR, Fischer TK, Melbye M Seroprevalence and risk factors for Helicobacter pylori infection in Greenlanders. Helicobacter. 2005 Oct;10(5):433-42.

20. Lehours P, Yilmaz O. Epidemiology of Helicobacter pylori infection. Helicobacter. 2007 Oct;12 Suppl 1:1-3.

Received September 23, 2010 Accepted in revised form December 7, 2010 